\title{
Paediatrics in Amsterdam
}

\author{
Ernst Eber*, Paul Aurora*, Karin C. Lødrup Carlsen`, Anders Lindblad ${ }^{+}$, \\ Jeannette E. Dankert-Roelse ${ }^{\S}$, Robert I. Ross-RusselI ${ }^{f}$, Steve W. Turner**, \\ Fabio Midulla\#\# and Gunilla Hedlin ${ }^{\text {"थ }}$
}

\begin{abstract}
The aim of this update is to describe the paediatric highlights from the 2011 European Respiratory Society (ERS) Annual Congress in Amsterdam, the Netherlands. Abstracts from all seven groups of the ERS Paediatric Assembly (Paediatric Respiratory Physiology, Paediatric Asthma and Allergy, Cystic Fibrosis, Paediatric Respiratory Infection and Immunology, Neonatology and Paediatric Intensive Care, Paediatric Respiratory Epidemiology, and Paediatric Bronchology) are presented in the context of current literature.
\end{abstract}

KEYWORDS: Asthma, bronchoscopy, cystic fibrosis, epidemiology, lung function, respiratory infection

$\mathbf{T}$ he 2011 European Respiratory Society (ERS) Annual Congress in Amsterdam, the Netherlands, included a large paediatric programme with numerous high-quality scientific presentations. For those colleagues who could not attend particular sessions, or even the whole Congress, this update will review the highlights of the abstracts presented by the Paediatric Assembly. These abstracts were selected by the Chairs from each of the paediatric scientific groups and are discussed in context of the current literature. Due to the large number of contributions to the Congress this summary cannot be comprehensive, but rather aims to address schemes of new research in major areas of paediatric respiratory medicine.

\section{PAEDIATRIC RESPIRATORY PHYSIOLOGY Forced oscillation}

Several previous studies have reported changes in forced oscillation measures in asthmatic children following bronchodilatation [1], but there are limited data regarding such responses in health, and regarding relationships with asthma symptoms. SIMPSON et al. [2] presented data from 760 healthy children undergoing lung function testing using a commercial forced oscillation device. They described changes in the area under the reactance curve following bronchodilator, and calculated reference ranges that were related to baseline lung function, height and sex. Albloushi et al. [3] related forced oscillation changes with bronchodilator (resistance and reactance at $8 \mathrm{~Hz}$ ) to baseline respiratory symptoms in children with mild asthma. Reactance changes after bronchodilator were significantly larger in those children reporting recent wheeze, whilst no difference was seen in resistance changes.

\section{Plethysmography}

In 1997, KLUG and BISGAARD [4] reported a method for measuring specific airway resistance (sRaw) plethysmographically in preschool children, utilising the one step calculation of $\mathrm{DAB}$ and ALEXANDER [5]. In this seminal paper, the authors investigated the effects of seating an adult in the plethysmograph with the child, breathing frequency and electronic compensation for phase shift in non-BTPS (body temperature $\left(37^{\circ} \mathrm{C}\right)$ and pressure (generally same as ambient), saturated $(47 \mathrm{mmHg}))$ conditions. COUTIER et al. [6] readdressed the last of these questions in finding that sRaw measured during tidal breathing in young healthy children is significantly higher than when measured during panting manoeuvres. The authors hypothesised that software algorithms are unable to correct for thermal changes during tidal breathing as effectively as they can during panting.

There has been much progress in recent years in developing more detailed and sophisticated reference values for lung function measures from preschool years to adulthood [7], much of which is linked to the Global Lungs Initiative, which was founded with the support of the ERS (www. lungfunction.org). However, reference equations for infant lung function measurements remain limited due to paucity of data. NGUYEN et al. [8] reported plethysmographic data from 140 infants. They examined the relationships between tidal volume and respiratory compliance over a range
AFFILIATIONS

*Dept of Paediatrics, University Children's Hospital, Medical University of Graz, Graz, Austria. -Dept of Paediatric Respiratory Medicine, Great Ormond Street Hospital for Children, London,

**Dept of Child Health, University of Aberdeen, Aberdeen, and ${ }^{f}$ Dept of Paediatrics, Addenbrooke's Hospital, Cambridge, UK.

'Dept of Paediatrics, Oslo University Hospital and the Faculty of Medicine, University of Oslo, Norway. + Gothenburg CF centre, Queen Silvia Children's Hospital, Gothenburg, and

**Astrid Lindgren Children's Hospital, Karolinska University Hospital, Stockholm, Sweden. ${ }^{\S}$ Dept of Paediatrics, Atrium Medisch Centrum Parkstad, Heerlen, The Netherlands.

\#\# Dept of Paediatrics, Sapienza University of Rome, Rome, Italy.

\section{CORRESPONDENCE}

E. Eber

Klinische Abteilung für Pulmonologie und Allergologie, Univ.-Klinik für Kinder- und Jugendheilkunde Medizinische Universität Graz Auenbruggerplatz 34/2 8036 Graz Austria

E-mail: ernst.eber@medunigraz.at

Received:

Dec 272011

Accepted after revision: Jan 192012

First published online: Feb 232012 
of age and body weight and concluded that simple correction for body weight is inadequate as it would result in an overestimation of predicted range for both parameters in the youngest infants and an underestimation in older infants. They suggested collecting a larger multicentre dataset to produce equipment-specific regression equations.

\section{Multiple breath washout}

A good volume of novel research from multiple breath washout (MBW) measurements has been published over the past decade [9]. A number of groups reported studies aimed at bringing this technique to the clinic, through the testing of two recently released commercial instruments. FuCHS et al. [10] described validation of an ultrasonic flow-sensor based commercial MBW system. They assessed accuracy of calculation of functional residual capacity (FRC) from nitrogen MBW using a novel lung model at a variety of FRC target volumes, using different respiratory rates and tidal volumes. Within-test repeatability of measurements was $<0.76 \%$; mean difference between target FRC and measured FRC was $3.28 \%$. The same authors, with further collaborators, reported feasibility and variability data using the same commercial equipment to collect lung clearance index (LCI) measurements in healthy children and adolescents at eight cystic fibrosis (CF) centres across Germany and Austria [11]. Intercentre variability was low at $2.9 \%$, but overall success rates were disappointing at $75.5 \%$. SINGER et al. [12] described bench validation of an alternative commercial nitrogen MBW instrument, also based on an ultrasonic flow-meter, but with a mainstream $\mathrm{CO}_{2}$ sensor and a sidestream $\mathrm{O}_{2}$ sensor. Again they used a lung model to measure a range of FRCs at varying tidal volumes and respiratory rates. The mean difference between measured and predicted FRCs in their study was $0.04 \%$. VIKLUND et al. [13] reported MBW results from 10 adolescent and adult subjects with CF comparing the gold standard SF-6 mass spectrometer-based MBW system to an ultrasonic flow-meter nitrogen washout system. They used very similar software algorithms to calculate FRC and LCI from both instruments. While FRC values from the two instruments were similar, the $\mathrm{N}_{2}$ LCI was significantly higher than the SF-6 LCI. On a related topic, LUM et al. [14] reported normal LCI data from 359 healthy subjects aged from birth to 19 yrs. Subjects were tested in London, UK, and Gothenburg, Sweden, using identical mass spectrometer hardware and software. The authors reported that LCI was constant from preschool years into adolescence, but significantly higher during infancy.

\section{Cough and expiration reflexes}

Forceful expiration in response to a stimulus can be subdivided into the cough reflex (CR), which is preceded by deep inspiration, or the expiration reflex (ER), a single expiratory effort [15]. The two reflexes are postulated to involve differing neural pathways, and to have different functions. VARECHOVA et al. [16] studied CR and ER in rabbits during different epochs of inspiration and expiration. In order to perform the study the researchers first had to demonstrate that ER could be elicited by a short, punctuate stimulus of the tracheal mucosa. They observed that CR incidence increased from $43 \%$ in early inspiration to $56 \%$ in late inspiration, but was almost absent in early expiration. Conversely, the incidence of ER increased throughout inspiration and further into early expiration, but then decreased into late expiration. The authors concluded that these different patterns during phases of breathing imply distinct control mechanisms.

\section{Post-natal lung development}

ScHUlz et al. [17] described an intrapulmonary deposition study in anaesthetised, intubated, spontaneously breathing rats. Aerosol concentration as a function of respiratory volume was determined by aerosol photometry. The highest deposition per breath was noted at the 35th post-natal day, being lower in both younger and older rats. This indicated that total deposition and deposition per unit time and surface area was higher in the developing rather than adult rat lung. The authors calculated that the equivalent developmental stage in human lungs would correspond to an age of 8 yrs and concluded that children at this age may, therefore, be more susceptible to airborne environmental health hazards.

\section{Immune activation}

Leukocyte-associated immunoglobulin-like receptor (LAIR)-1 is a collagen receptor that increases the threshold for activating signals on immune cells, thereby inhibiting immune activation [18]. HoubEN et al. [19] measured airway compliance and resistance at age 1 month in 152 newborn infants and related this to LAIR-1 collected from amniotic fluid during labour and from cord blood. Amniotic fluid LAIR-1 was lower in children who wheezed at age of 6 and 9 months, and airway compliance and amniotic fluid LAIR-1 were positively correlated. This correlation did not change by adjustment for sex or maternal smoking. Airway resistance was not correlated. This study underscores the clinical impact of intrauterine immune activation.

\section{PAEDIATRIC ASTHMA AND ALLERGY Severe asthma}

Severe asthma has received increased attention in past years, with a series of three review papers in the European Respiratory Journal describing clinical presentation [20], assessment [21] and pharmacological treatment [22] of severe asthma in childhood. Moss et al. [23] reported omalizumab to reduce the required steroid dose in children $\leqslant 3$ yrs of age, with a corresponding improved quality of life. Whereas PITTS et al. [24], in a retrospective chart review, found severe side-effects in two out of 13 children (aged 9-17 yrs), with anaphylaxis and cardiomyopathy, respectively. FROST et al. [25] demonstrated that the use of a multi-disciplinary approach to assess severe asthma reduced the number of children eligible for omalizumab from 17 to seven out of 19 as modifiable factors were identified in the remaining children. The need for common approaches and definitions, collaboration to identify phenotypes and underlying mechanisms, as well as clinical trials of treatment options in this group of children was highlighted in the Paediatric Year in Review session at the ERS Congress. The higher burden of severe disease was recently confirmed in 6-12-yr-old children and a decrease in economic costs with improved control of disease was demonstrated [26].

\section{Roles of allergy and infections}

The individual contributions of allergy and viral infections in the initiation of asthma, as well as in asthma exacerbations, are still being debated. A randomised, controlled trial of 60 weeks of anti-immunoglobulin E treatment added to guideline asthma 
medication improved asthma control and nearly eliminated the seasonal peaks of exacerbations in US inner-city adolescents and young adults with moderate or severe asthma [27]. This underpins the interaction between infections and allergen exposure in asthma development [28-30]. It is likely that deficiencies in anti-viral activity and epithelial barrier increase the susceptibility to severe respiratory infections in children with asthma [31]. After identification of impaired interferon production in mild-to-moderate asthma this has now also been demonstrated by EDWARDS et al. [32] in cultured bronchial epithelial cells from children with severe asthma. Allergy probably plays an important role in virus-triggered wheeze [29] and asthma development. The underlying mechanisms are unclear, but the eosinophil has been suggested as a common cell in allergy, asthma and viral infections [30]. In a mouse model of rhinovirus-induced asthma exacerbation, BARTLETT et al. [33] observed three different modes of allergen-virus interaction: allergen-induced, augmented by virus; virus-induced, augmented by allergen; and allergen and virus additive.

\section{Asthma phenotypes}

At present, there is still no agreement on how many phenotypes of asthma there may be in childhood, and how to identify them. The term "wheeze" in early life is a fuzzy phenotype [29], and does not necessarily represent asthma. Nevertheless, using advanced statistical methods, such as latent class analysis, temporal childhood phenotypes were identified in the first 8 yrs of life in two different cohorts (the British ALSPAC and the Dutch PIAMA birth cohorts) [34]. Despite remarkable similarities between the six and five classes identified, respectively, as well as their correlates with traits such as allergic sensitisation, lung function and asthma [34], this approach indicates classification based upon one criterion only. VAN DE KANT et al. [35] measured inflammatory markers in exhaled breath condensate and used a similar temporal approach to wheeze phenotypes (never, early-transient, intermittent and persistent); they found that children with intermittent and persistent wheeze at age 5 yrs had already had elevated inflammatory markers at preschool age, indicating augmented airway inflammation in these children. As yet, we have very limited knowledge of the onset and extent of remodelling in preschool children. In a biopsy study, O'REILLY et al. [36] demonstrated increased reticular basement membrane (RBM) thickness in preschool wheezers compared to controls. Follow-up at school age showed that children with and without asthma had similar RBM thickness in their preschool biopsies. However, children with increased airway smooth muscle in preschool age had a 10-fold increased risk of asthma at school age.

Very recently, various approaches were suggested to predict immunological correlates to varying phenotypes of asthma. In a publication from the US Severe Asthma Research Program it was suggested that intermediate asthma phenotypes could be predicted using bronchoalveolar lavage (BAL)-derived cytokines [37]. This proof of principle study used intermediate quantitative asthma phenotypes (determined by extreme values of BAL eosinophils and neutrophils, bronchodilator response to albuterol and methacholine sensitivity), testing five different statistical prediction models in order to identify multidimensional BAL cytokine profiles. Furthermore, JAMES et al. [38] found increased levels of the chitinase-like protein YKL-40 in children with severe asthma compared to healthy children, and suggested that serum YKL-40 might be a potential new biomarker of airway inflammation in children. In a study of children aged 6 yrs, ScHOOS et al. [39] suggested that exhaled nitric oxide fraction $(F \mathrm{eNO})$ and bronchial responsiveness are associated and continuous traits regardless of asthma, and that these surrogate markers should therefore be interpreted with caution in diagnosing asthma. Another study suggested that three clusters of patients had a complex interaction with three clusters of cytokines [40]. This work was performed in adults, but the approach is also highly relevant in paediatrics. The large EU-funded (FP7) MeDALL study was initiated in 2011 to generate novel knowledge on the mechanisms of initiation of allergy and to propose early diagnosis, prevention and targets for therapy. The approaches rely on the applications of "omics" techniques (proteomics and metabolomics) with high-throughput measurement platforms integrated with biological and clinical data, largely from birth cohort studies throughout Europe [41].

\section{Genetics and epigenetics}

Genetic and epigenetic studies have provided some new insight into asthma susceptibility. Variation at the 17q21 asthma locus, encoding the ORMDL3 and GSDML genes, appears to specifically increase the risk for childhood-onset asthma [42]. Single nucleotide polymorphisms within several genes showed associations to asthma and obesity, but none of these associations were significant after correction for multiple testing [43]. Gene-environment interactions were demonstrated in different populations, with an interaction between tobacco smoke exposure and the alpha subunits of the nicotinic acetylcholine receptor for bronchial hyperresponsiveness in children [44]. Furthermore, the effect of day care on sensitisation and atopic wheezing was reported to differ in children with different variants of the Toll-like receptor 2 gene [45]. BuKVIC et al. [46] reported endotoxin exposure to be associated with a decreased risk of asthma in the whole population of investigated Croatian children but the effect of endotoxin exposure on asthma was found to differ among children with different variants of the MD-2 gene. Recent epigenetic studies have found DNA methylation in ARG1 and ARG2 to be associated with FeNO in children with asthma, thereby suggesting a possible role for epigenetic regulation of nitric oxide production [47]. Increased CD14 methylation from $2-10$ yrs of age in children from a Norwegian birth cohort was found to be inversely correlated with soluble CD14 levels at 10 yrs of age [48]. The role of epigenetic mechanisms in early life exposures, particularly during in utero life, was recently reviewed [49] and is likely to gain further attention in the next few years.

\section{Asthma management}

Managing asthma involves control of the disease by pharmacological, as well as other, measures. Ciclesonide has recently been approved for children $\geqslant 12$ yrs of age in many countries, and being a pro-drug has a proposed beneficial effect to sideeffect ratio, with demonstrated effects on asthma control in adults [50]. In line with the latter study, in a large multicentre study in preschool children, BRAND et al. [51] found a modest reduction of exacerbation rates and improved lung function with ciclesonide. 
Several studies have recently reported improved asthma control and reduced severity of disease in programmes of patient education [52-54]. This was also highlighted by SHEIKH et al. [55] with a study showing the need to train the trainers and by BIRD et al. [56] with a systematic review of the underlying reasons for barriers to asthma management. Programmes have been tested in low-income, inner-city environments with effects in children [57], and education appears to be effective in improving asthma control and preventing acute exacerbations in adolescents [53], although written action plans did not appear to significantly improve asthma control [58]. Furthermore, children with allergic diseases are at a disadvantage in day-care and schools. There is a general lack of knowledge and systematic approach to ensure medical facilities as well as relevant adjustments to secure the environment for children with allergic diseases. This has recently been investigated by a Task Force report on how to manage the allergic child at school [59].

\section{CYSTIC FIBROSIS}

\section{New treatments}

During the past years huge efforts have been made in developing new types of drugs to treat the basic defect in cystic fibrosis (CF), called CFTR potentiators and correctors. In a late-breaking abstract, PLANT et al. [60] reported that VX-770 (a CFTR potentiator) in a phase III trial including patients with the G551D mutation where CFTR is expressed on the apical surface but does not function properly, increased forced expiratory volume in $1 \mathrm{~s}$ (FEV1) by $10.4 \%$ at week 24 and $10.1 \%$ at week 48 in the treatment arm while the placebo group was unchanged. The risk of pulmonary exacerbations decreased by $55 \%$, and sweat chloride decreased by 48 $\mathrm{mmol} \cdot \mathrm{L}^{-1}$ through week 48 [61]. These are very exciting and promising results for all patients with this type of mutation. At present, no more information has been published regarding the ongoing phase III clinical trial with PTC124 in patients with premature stop codons [62]. Denufosol, a P2Y2 receptor agonist that activates alternative chloride channels, had previously shown promising results in phase II studies [63]. Unfortunately, this drug failed in a phase III trial and the project has now been halted. Studies of other drugs aiming to overcome the degradation of CFTR in class 2 mutations, such as deltaF508, are ongoing.

Mannitol, a sugar alcohol, functions as a hyperosmolar agent and is presently used for bronchial provocation testing. By creating an osmotic gradient it is thought to facilitate water movement into the lumen of the airways, increasing the water content in the airway surface liquid and thereby improving mucus clearance. A phase III study has shown a significant improvement in FEV1 and pulmonary exacerbation rate during a period of 26 weeks, independent of rhDNase usage [64]. Mannitol (Bronchitol®) was approved by European Medicines Agency for use in patients aged $\geqslant 18$ yrs as an add-on therapy to best standards of care as of October 2011.

As free elastase is thought to be a major cause of the development of bronchiectasis in CF [65], neutrophil elastase inhibitors could be a potential way to influence the progression of CF lung disease. There are now such substances available.

\section{Lung function and imaging}

It is difficult to monitor early CF lung disease. FEV1 is not sensitive enough to mirror the progression of early lung disease and the correlation between FEV1 and structural lung damage is poor. Another problem is the difficulty to measure lung function in children aged $<5-6$ yrs. In younger children, MBW to measure the LCI and the raised volume rapid thoracic compression technique measuring FEV0.5 can also be used [66]. LCI reflects the degree of ventilation inhomogeneity in the peripheral airways where pathology starts in CF. Highresolution computed tomography (HRCT) may detect early structural lung damage in children with CF [67]. The place for these methods and parameters in routine care and as endpoints in studies is presently discussed. THIA et al. [68] performed MBW and raised volume techniques in $\mathrm{CF}$ babies diagnosed by newborn screening (NBS) and healthy controls at age 3 months and $1 \mathrm{yr}$. They found an improvement at $1 \mathrm{yr}$ in both LCI and FEV0.5 and also in nutritional status, showing a satisfying effect of standard therapy. SIMPSON et al. [69] assessed the impact of pulmonary infection and the presence of free neutrophil elastase as a marker of airway inflammation on ventilation distribution in infants and young children with CF. They could not find an association between LCI and infection or inflammation but reported moment ratios to be more sensitive to lung disease associated with infection than LCI. LINDBLAD et al. [70] compared mean LCI at age 1-4 yrs with LCI, FEV1 and chest radiograph abnormalities (Northern score) at 7 yrs of age. Increased LCI in the preschool years only correlated with Northern score, i.e. with the degree of structural lung changes at 7 yrs of age.

In children with CF aged 1-5 yrs, MотT et al. [71] showed that the presence and extent of bronchiectasis is underestimated with expiratory scans alone compared with inspiratory scans. Therefore, it appears one can neither lower the radiation dose nor avoid the anaesthesia needed for an inspiratory scan in small children. Magnetic resonance imaging (MRI) does not involve radiation but its sensitivity to detect early CF lung disease has been questioned previously [72]. EICHINGER et al. [73] reported that MRI of the lung is sensitive to detect abnormal morphology, function and response to therapy in early CF lung disease, and suggested that MRI may be suitable for non-invasive diagnostic monitoring of disease severity and may serve as a novel end-point for clinical trials in early CF lung disease.

\section{Airway infection}

Aspergillus fumigatus is a common microorganism in $\mathrm{CF}$ sputum and BAL fluid. Apart from causing allergic bronchopulmonary aspergillosis there is growing evidence that A. fumigatus can also have a direct negative effect on lung function. In a retrospective study from the same group, THURSFIELD et al. [74] and ADAMs et al. [75] found that A. fumigatus in the airways of CF children, whether identified on direct smear or culture, is associated with worse lung function, despite the use of significantly more intravenous antibiotics in the group with A. fumigatus as compared to the one without. VANDERHELST et al. [76] underlined the increasing prevalence of chronic infection with Methicillin-resistant Staphylococcus aureus in CF patients and showed an association with a particular genotype and a larger decline in lung function. 
Several abstracts also reported an increasing prevalence of Stenotrophomonas maltophilia and Achromobacter xylosoxidans in CF patients indicating that it is a growing clinical problem [77-79]. Asherova et al. [80] showed a high prevalence of Achromobacter in the toilets and sinks of an infectious ward, stressing that hygienic measures are to be improved. The authors suggested, but did not prove, a possible transmission route from the hospital environment and personnel hands to the patients.

Rhinovirus, like other viruses, has been shown to trigger pulmonary exacerbations and has been associated with impaired virus clearance from CF airway epithelium [81]. KIENINGER and co-workers $[82,83]$ reported evidence for an impaired early innate anti-viral response in cultured CF airway epithelial cells and also compared prevalence and the load of rhinovirus in BAL fluid from children with $\mathrm{CF}$, non-CF bronchiectasis, asthma and healthy controls. They found a higher prevalence in CF compared to the other groups and also the highest load of rhinovirus, especially in children with an active exacerbation at the time of the BAL, and suggested a possible role for rhinovirus in CF lung disease progression.

To improve quality of life in patients with CF it is important to decrease the number of exacerbations or start treatment early. By home monitoring FEV1 three times per week, ROBROEKS et al. [84] were able to detect an exacerbation 10 to 4 days before it became clinically evident.

To evaluate the effect of NBS on the clinical status of the patients later in life, a follow-up of the patients born in the 3 yrs prior to when NBS started in 1981 in New South Wales (Australia) and the 3 yrs after was performed by DIJK et al. [85]. The children showed significantly lower Pseudomonas colonisation, better lung function and nutritional state at the time of transfer to the adult clinic at 18 yrs of age for the patients diagnosed by NBS.

\section{Diagnosis and care}

Nasal potential difference has been used in diagnostic algorithms for diagnosing CF where routine tests have not been conclusive. COHEN-CYMBERKNOH et al. [86] evaluated the use of rectal biopsies for intestinal current measurement as a method to discriminate between $\mathrm{CF}$ and non-CF patients. The group found intestinal current measurement discriminative and recommended more studies to confirm their results.

Finally, as a very important reminder of the unequal CF care across Europe, DRACEA et al. [87] reported the outcome from a centre in Romania and the impact of lack of funding. To help to overcome these outcome differences is a huge task but of extreme importance for the ERS.

\section{PAEDIATRIC RESPIRATORY INFECTION AND IMMUNOLOGY}

\section{Bronchiolitis and pneumonia}

Endogenous, as well as exogenous, factors in common respiratory infections such as bronchiolitis and childhood pneumonia were discussed at the 2011 ERS Congress.

Wheezing is a common symptom in young children and young children are prone to bacterial infection. Combining these two facts has led to the hypothesis that positive bacterial cultures might be associated with wheezing episodes in young children independent of viral infections [88]. How bacteria may contribute to the development of preschool wheeze is largely unknown. VAN DE KANT et al. [89] investigated whether a cohort of preschool children with recurrent wheeze differed from healthy controls in bacterial colonisation in the upper respiratory tract and in pro-inflammatory markers in exhaled breath condensate. They found no evidence for an association between bacterial colonisation or infection and preschool recurrent wheeze [89].

There has been a long-standing hypothesis that vitamin D deficiency might be associated with an increased susceptibility for respiratory tract infections (RTIs), because vitamin D plays an important role in modulating the innate immune response against infections [90]. PILlai et al. [91] showed in their systematic literature review that low vitamin D levels are strongly associated with an increased risk of acquiring acute RTIs, both viral and bacterial, and with increased RTI-related morbidity. Two intervention studies have suggested a protective effect by vitamin D supplementation in both toddlers and school age children [92, 93].

Respiratory syncytial virus (RSV) bronchiolitis is a major cause of infant morbidity and mortality. In earlier studies a beneficial effect of nebulised hypertonic saline in infants with moderate acute bronchiolitis has been reported [94]. At the ERS Congress, Teunissen et al. [95] and NennA et al. [96] presented rather disappointing results. The two studies, both appropriately powered, showed no effect of $7 \%$ or $3 \%$ hypertonic saline given by inhalation to infants hospitalised for moderate acute bronchiolitis on duration of hospital stay or clinical scores. Therefore, it remains questionable as to whether nebulisation of hypertonic saline should be introduced as a standard treatment option for infants hospitalised for moderate acute bronchiolitis.

The increased risk for a severe course of RSV bronchiolitis in prematurely born infants is well known [97]. In a large cohort, BUESCH et al. [98] assessed the independent risk of respiratory distress syndrome (RDS) on hospitalisation for a lower RTI and found that late preterm infants with RDS at birth are five times more likely to be hospitalised during the first year of life compared to late preterm infants without RDS. The costs of such hospitalisations are considerable. SHEFALI-PATEL et al. [99] showed that the adjusted mean difference in costs of care in late preterm babies with RSV lower RTI was $£ 11,116$ compared to infants without respiratory problem. As no effective treatment options are currently available for acute viral bronchiolitis, prevention will be the most effective costreducing factor.

\section{Primary ciliary dyskinesia}

Electron microscopy is often considered as the gold standard for diagnosing primary ciliary dyskinesia (PCD) [100]. In a cohort of paediatric PCD patients, NAUTA et al. [101] showed that in $29 \%$ of patients with PCD (proven by other diagnostic methods, including light microscopy and epithelial cell cultures) electron microscopy findings were completely normal. The authors concluded that a diagnosis of PCD cannot rely on a single technique, and thus recommended to combine at least two diagnostic techniques and that epithelial cell 
cultures should be an integral part of the diagnostic work-up. It is believed that in the future genetic studies may further improve diagnostic accuracy.

\section{NEONATOLOGY AND PAEDIATRIC INTENSIVE CARE Neonatology}

Neonatal resuscitation remains an area of increasing interest. The use of bag valve mask devices in the delivery room and neonatal intensive care unit has been under scrutiny. HARTUNG et al. [102] showed that different devices will provide different levels of pressure and flow to infants, depending on factors such as the leak. At a practical level this emphasises the care with which mask ventilation should be administered as different models can deliver quite different pressures and flows.

In a case-control study, GOROVENKO et al. [103] reviewed the angiotensin-converting enzyme (ACE) genotype in infants with severe perinatal asphyxia. Their data suggested that a DD genotype for ACE was much more common in severe birth asphyxia. Whether this reflects that such patients are at greater risk of hypoxic injury is unclear.

Historical use of pressure-controlled ventilation, used in part due to the difficulties of accurate volume control at low volumes, may give rise to excessive tidal volumes. CHOWDHURY et al. [104] reported that pressure-limited ventilation in infants born at or near term frequently results in volumes outside the normal tidal range, and that even within that range work of breathing may be increased at lower volumes. Modern ventilators can control volume in even very preterm infants and may reduce the risk of volutrauma and barotrauma. An important aspect of barotrauma relates to the infants' spontaneous respiratory pattern during mechanical ventilation. CHOWDHURY et al. [105] evaluated spontaneous respiratory effort in a group of ventilated infants receiving either synchronised intermittent mandatory ventilation (SIMV) or intermittent positive pressure ventilation (IPPV). In those on SIMV, most (75\%) showed active expiration, with a further $20 \%$ showing synchrony. For non-synchronous ventilation (IPPV) the pattern was different with $50 \%$ of the patients showing a prolonged expiratory phase. Understanding the different patterns of breathing associated with different ventilator settings should help clinicians better understand the risks of complications such as pneumothorax or other barotrauma.

The organisation of neonatal services in rural areas can be complex. BHANDARI et al. [106] presented a model adopted in Nepal that acted as a very useful guide to the benefits of geographically defined resource allocation. Clear pathways and a focus on local training are essential. For those that require air transport, WITHERs et al. [107] investigated 141 infants to assess the predictors of in-flight hypoxia. Depressingly, post-menstrual age, weight and sex were all non-predictive of hypoxia which appeared to be rather idiosyncratic. Staff should be prepared to administer oxygen for most infants, despite the logistical problems that this creates.

Further evidence of the long-term complications of neonatal lung disease continues to be evident. It has been shown that the respiratory burden of prematurity is probably bigger than previously thought [108]. Infants born only moderately premature (32-36 weeks gestation) were shown to have an increased incidence of respiratory morbidity, and this increased with increasing prematurity. CHOUKROUN et al. [109] have similarly found a high percentage $(60 \%)$ of school age children who were born at $<32$ weeks gestation with respiratory symptoms, and $54 \%$ of them had impaired lung function. In contrast, LIDBERG et al. [110], who investigated forced expiratory flows in 150 preterm and 100 term infants, found decreased flows in infants $<32$ weeks gestation (with increased risk of hospitalisation for RSV positive bronchiolitis) but similar expiratory flows in moderately preterm as compared to term infants.

\section{Paediatric intensive care}

At the other end of the spectrum, end of life issues in children and young adults with chronic respiratory conditions is an area that is often overlooked. In late stage $\mathrm{CF}$, there is some evidence that CT scanning may provide prognostic information although the variability between patients remains high [111]. Different patterns of injury may be seen from infection/ inflammation dominated to air trapping and hyperperfusion. There is considerable overlap between these in individual patients with different areas of the lungs showing different patterns, and the implication of these changes remains uncertain. Oxygen therapy in late stage disease has never been effectively shown to help, but a recent study concluded that overnight hypoxia is associated with more daytime symptoms [112]. This would suggest that administration of oxygen may have benefits in these patients beyond the maintenance of good saturations. Symptom assessment overall is probably inadequate in end-stage lung disease. Data from CF patients shows a substantial underestimation [113]. Major areas of undiagnosed problems include pain (especially chest pain in the late stages of disease) and bowel problems (both diarrhoea and constipation). Asking questions about these symptoms as part of a "symptom control" approach should be an important part of care.

BRUIJN et al. [114] presented data on children with acute lung injury. In a group of 98 ventilated patients, increased Creactive protein (CRP) levels were associated with increased mortality. Even after correction for cardiovascular organ failure, a $10 \mathrm{mg} \cdot \mathrm{L}^{-1}$ increase in CRP was associated with an increase in risk of mortality of $5 \%$.

Outcomes following lung transplantation in children continue to steadily improve [115]. There remains a mismatch between the number of children requiring transplants and the number of available donors, meaning that alternative approaches, such as donation after cardiac death, are being investigated [116].

\section{PAEDIATRIC RESPIRATORY EPIDEMIOLOGY Prematurity and reduced lung function}

The ALSPAC group has recently described the relationship between post-natal weight gain and respiratory outcomes among infants born with gestation appropriate weight [117]. КОтесHA et al. [118] applied their large dataset to address the issue of "late preterm birth" and reported that children born at 33-34 weeks gestation (but not 35-36 weeks) have significantly lower lung function values at $8-9$ yrs of age similar to the decrements observed in the 25-32-week group; most of these differences were reduced by 14-17 yrs of age. An association 
between extremely premature delivery and reduced spirometry in childhood is well-established. VOLLSAETER et al. [119] reported that this association persists into early adulthood. VOGT et al. [120] used a whole population dataset to relate gestation to prescription of inhaled corticosteroids and reported that there was a $10 \%$ increase of inhaled corticosteroid usage in 6-19 yr olds born at 37-38 weeks compared to those born at 39-41 weeks, and an odds ratio of $>2$ for those born at 24-28 weeks. In summary, gestation may be a more important determinant than birth weight for respiratory outcomes and the risk of life-long respiratory morbidity associated with "short" gestation may first emerge at 38 weeks.

\section{Age at onset of reduced lung function}

Some studies found childhood asthma to be associated with very early abnormalities in physiological measurements [121] but others did not [122]. Duijs et al. [123] related physiological measurements to phenotypes, and this extended their previous work relating wheezing pattern to six phenotypes by latent class analysis [124]. In adolescence, the most profound abnormalities were present in those with onset of wheeze after the age of 18 months and persistent wheezing [123]. These findings are consistent with those from Mullane et al. [125] who were able to demonstrate that the persistent wheeze group already had reduced lung function at 1 month of age. VAN DER GUGTEN et al. [126] related infant lung function to later wheeze and found increased total respiratory resistance preceded early wheeze and reduced compliance preceded persistent wheeze at 5 yrs of age. TURNER et al. [127] and SONNENSCHEIN-VAN DER VOORT et al. [128], both relating fetal ultrasound measurements to respiratory outcomes, provided further evidence to support the concept that lung function is determined at an early stage of development. In the study by TURNER et al. [127], persistent low growth in the first and second trimesters was associated with reduced lung function and increased risk for asthma. SONNENSCHEIN-VAN DER VOORT et al. [128] reported that fetal growth restriction from the second trimester to birth was associated with increased wheeze, particularly in association with post-natal "catch up" growth. In summary, the evidence presented indicated that reduced lung function and associated symptoms appear to be determined in early life.

\section{Post-natal exposures and reduced lung function}

Although lung function may be determined by antenatal factors, early post-natal exposures are also important but can be more challenging to assess, factors include: infection [29], and inhaled [129] and dietary exposures [130]. STRIPPOLI et al. [131] modelled ambient air quality throughout childhood and performed spirometry in children aged 9-13 yrs. They found that early exposure to inhaled particles with a $50 \%$ cut-off aerodynamic diameter of $10 \mu \mathrm{m}$ was associated with reduced forced vital capacity but no other spirometric indices. DOGARU et al. [132] related breast feeding to alveolar size using MRI technology. Although the study was underpowered there was evidence of an interaction where breastfeeding offset the reduction in lung volumes associated with maternal asthma. In a cross-sectional study, WONG et al. [133] found indoor endotoxin exposure to be positively correlated with wheeze. In summary, these studies demonstrate how new methods might be used to understand the relative importance of post-natal factors in the development of asthma. To further complicate the analysis, it is likely that the effects of these exposures may be modified by other exposures (e.g. second-hand tobacco smoke) and atopy [134].

\section{Respiratory symptoms in infancy}

The epidemiology of infant respiratory symptoms has been relatively neglected and the multinational EISL group ("Estudio Internacional de Sibilancias en Lactantes") presented two papers on this subject. GARCIA-MARCOS et al. [135] considered latitude to modify risk or protective factors for respiratory symptoms. For example, they reported how the apparent protective effect of breastfeeding was greater for infants native to countries of higher latitude (North or South) compared to their equatorial peers. In a second paper, GARCIAMARCos et al. [136] reported early respiratory infection to be the risk factor most strongly linked with early wheeze across all centres. In Latin American centres, breastfeeding was protective against early wheeze and, in Europe, reduced socioeconomic status and eczema increased the risk for wheeze. STRIPPOLI et al. [137] reported cough prevalence in infancy and its outcome. Cough prevalence was $17 \%$ in infancy, persisted in many individuals and remained at $12 \%$ for children aged 9 yrs. Infancy may include a critical window where exposures influence the developing respiratory system, and exposures may differ between populations.

\section{PAEDIATRIC BRONCHOLOGY}

\section{Technique and indications}

Flexible airway endoscopy is a standardised and important diagnostic tool for evaluating respiratory disorders in children [138]. The most frequent indication for bronchoscopy in children is the presence of chronic respiratory signs or symptoms, such as stridor and wheezing [138]. Recurrent or persistent pneumonia represents another indication for airway endoscopy. GOKDEMIR et al. [139] performed a retrospective study in children who underwent flexible airway endoscopy for recurrent or persistent pneumonia. They reported that an underlying aetiology could be identified in $32 \%$ of the patients, the most frequent being foreign body aspiration $(12 \%)$ and congenital airway anomalies (9\%). Even though recurrent pneumonia is a well-established indication for bronchoscopy, this study is one of the first to provide evidence in a large cohort of patients that this technique is diagnostically useful in this indication.

Chronic cough is another indication for bronchoscopy in children. Again in a retrospective study, Douros et al. [140] evaluated children with chronic wet cough and compared the effectiveness of flexible bronchoscopy and HRCT in detecting airway abnormalities. They reported that HRCT can detect airway wall thickening and bronchiectasis, and that the severity of the findings correlated positively with the duration of the clinical symptoms and the intensity of neutrophilic inflammation in the airways. As HRCT scanning was less sensitive than flexible bronchoscopy in detecting airway abnormalities, it was suggested that the two modalities should be considered complementary for evaluating prolonged wet cough. This study confirms previous studies showing that 
bronchoscopy is an important diagnostic technique for evaluating children with chronic wet cough [141].

The availability of smaller bronchoscopes has expanded the range and indications for this technique in neonates and premature babies. In symptomatic preterm infants who were intubated at birth MONDEJAR-LOPEZ et al. [142] diagnosed abnormal endoscopic findings in all infants. The most common were airway malacia $(59 \%)$, followed by laryngotracheal cyst or granuloma $(45 \%)$, left vocal cord paralysis $(33 \%)$, subglottic stenosis $(30 \%)$, supraglottic oedema $(21 \%)$, and tracheal stenosis $(7 \%)$. This study confirms a previous report demonstrating the importance of this technique in preterm infants with respiratory symptoms who were intubated after birth [143].

\section{Special procedures}

Several special procedures can be performed through the working channel of the flexible bronchoscope [138]. BAL is a useful technique to increase the diagnostic yield of flexible bronchoscopy for clinical and research purposes [144]. MONDEJAR-LOPEZ et al. [145] described the incidence of positive bacterial cultures in BAL fluid from children with chronic respiratory symptoms and assessed the differences between children with and without bronchiectasis. The most common bacteria were Haemophilus influenzae and Streptococcus pneumoniae, followed by $S$. aureus, Pseudomonas aeruginosa and Klebsiella pneumoniae. While a positive bacterial culture in BAL fluid was found to be more common in children with bronchiectasis, the role of bacteria in other non-suppurative lung diseases should also be taken into account. This study underlines the importance of obtaining BAL cultures during flexible bronchoscopy, especially in children with chronic respiratory symptoms.

In a study designed to investigate whether BAL eosinophilia could identify specific clinical phenotypes of asthmatic and/or atopic children, SNIJDERS et al. [146] analysed BAL fluid and bronchial biopsies from 107 children. Children with high eosinophil counts in BAL fluid also had high eosinophil counts in the tissue. BAL eosinophilia was observed in $16 \%$ of the children and severe eosinophilia in $7.5 \%$. Atopic asthmatics were more frequent in the so-called intermediate and severe eosinophilic groups, non-atopic asthmatics were equally distributed, and atopic children without asthma were observed in both the non-eosinophilic and severe eosinophilic groups. This study is important because it adds new information on lower respiratory inflammation not only in children with various asthmatic phenotypes, but also in atopic children without asthma.

Biopsy specimens can be taken from the mucosa, endobronchial lesions or lung parenchyma [138]. Unfortunately, due to the small sizes of the working channels of the paediatric bronchoscopes the material obtained with transbronchial biopsies is often insufficient. In a retrospective study, DE MIR et al. [147] reviewed 137 transbronchial biopsy samples, of which 25 were disregarded due to lack of information. In 22 procedures, a 3.6- $\mathrm{mm}$ flexible bronchoscope was used and in the rest a 4.9-mm instrument. 100 (90\%) biopsies were considered adequate (91\% of the biopsies taken with the 1.8$\mathrm{mm}$ forceps and $63 \%$ taken with the 1.1-mm forceps). In the non-transplant population, the biopsies were diagnostic in $75 \%$ of the patients. The most frequent complications were bleeding $(17 \%)$, pneumothorax $(4.5 \%)$ and bronchospasm (3\%). The investigators concluded that transbronchial biopsy through the flexible bronchoscope is a relatively safe and effective method for diagnosing and monitoring lung diseases in selected children. The 3.6- $\mathrm{mm}$ bronchoscope and 1.1-mm forceps performed poorly; thus, it was suggested to use the $1.8-\mathrm{mm}$ forceps whenever possible. This study confirms previous reports that recommended use of an adult or rigid bronchoscope whenever feasible in order to achieve a higher diagnostic yield [148].

Suspected foreign body aspiration is a major indication for flexible airway endoscopy in children, especially because physical examination and radiology are often poorly sensitive. MODARESI et al. [149] retrospectively reviewed 188 paediatric patients with a history suggestive of foreign body aspiration and reported confirmation of foreign body aspiration in 112 $(60 \%)$ children. They concluded that bronchoscopy should be performed in all children with a positive history of choking, even in the presence of a normal physical examination. This study confirms previous reports demonstrating that neither physical examination nor chest radiograph findings are sufficiently sensitive or specific [150].

In conclusion, many interesting and promising results were reported, emanating from studies performed in children. These studies will be even more important as the awareness of the relationship between lung growth, childhood airway and lung diseases and respiratory diseases in adulthood increases [151].

\section{STATEMENT OF INTEREST}

A statement of interest for K.C. Lødrup Carlsen can be found at www. erj.ersjournals.com/site/misc/statements.xhtml

\section{REFERENCES}

1 Oostveen E, Dom S, Desager $\mathrm{K}$, et al. Lung function and bronchodilator response in 4-year-old children with different wheezing phenotypes. Eur Respir J 2010; 35: 865-872.

2 Simpson SJ, Calogero C, Palumbo M, et al. Area under the reactance curve: reference ranges and bronchodilator response (BDR) in healthy children. Eur Respir J 2011; 38: Suppl. 55, 570s.

3 Albloushi A, Park J, Stick S, et al. Relationship between lung function using forced oscillation technique (FOT) with recent symptoms in young children with asthma. Eur Respir J 2011; 38: Suppl. 55, 354s-355s.

4 Klug B, Bisgaard H. Measurement of the specific airway resistance by plethysmography in young children accompanied by an adult. Eur Respir J 1997; 10: 1599-1605.

5 Dab I, Alexander F. A simplified approach to the measurement of specific airway resistance. Pediatr Res 1976; 10: 998-999.

6 Coutier L, Bonabel C, Demoulin B, et al. Specific airway resistance is overestimated during tidal breathing vs panting in healthy children. Eur Respir J 2011; 38: Suppl. 55, 351s.

7 Stanojevic S, Wade A, Stocks J, et al. Reference ranges for spirometry across all ages: a new approach. Am J Respir Crit Care Med 2008; 177: 253-260.

8 Nguyen TTD, Hoo AF, Lum S, et al. Interpretation of passive respiratory mechanics in infants: should we normalise by body weight? Eur Respir J 2011; 38: Suppl. 55, 351s-352s.

9 Fuchs SI, Gappa M. Lung clearance index: clinical and research applications in children. Paediatr Respir Rev 2011; 12: 264-270. 
10 Fuchs S, Buess C, Gappa M. In vitro validation of nitrogen multiple breath washout using ultrasonic equipment. Eur Respir J 2011; 38: Suppl. 55, 355s.

11 Fuchs S, Ellemunter H, Eder J, et al. Multicentre feasibility and variability of measuring the lung clearance index in healthy volunteers. Eur Respir J 2011; 38: Suppl. 55, 570s.

12 Singer F, Abbas C, Viklund E, et al. Bench test of an $\mathrm{O}_{2} / \mathrm{CO}_{2}$ sensor based MBW system using a lung model. Eur Respir J 2011; 38: Suppl. 55, 353s.

13 Viklund E, Lindblad A, Robinson P, et al. Comparison of a new nitrogen multiple breath washout method to mass spectrometer SF6 washout in cystic fibrosis subjects. Eur Respir J 2011; 38 Suppl. 55, 354s.

14 Lum S, Sonnappa, S, Gustafsson P, et al. Lung growth and ventilation inhomogeneity in health. Eur Respir J 2011; 38: Suppl. 55,351 s.

15 Korpás J. Differentiation of the expiration and the cough reflex. Physiol Bohemoslov 1972; 21: 677-680.

16 Varechova S, Demoulin B, Poussel M, et al. Elicitability of defensive reflexes within the breathing cycle. Eur Respir J 2011; 38: Suppl. 55, 569s.

17 Schulz H, Eder G, Bolle I, et al. Micron-sized particle deposition in the developing rodent lung. Eur Respir J 2011; 38: Suppl. 55, $569 \mathrm{~s}$

18 Meyaard L. The inhibitory collagen receptor LAIR-1 (CD305). J Leukoc Biol 2008; 83: 799-803.

19 Houben M, Nordkamp MO, van der Ent K, et al. Newborn airway compliance is correlated with amniotic fluid soluble leukocyte-associated Ig-like receptor-1 (LAIR-1). Eur Respir J 2011; 38: Suppl. 55, 569s.

20 Hedlin G, Bush A, Lødrup Carlsen K, et al. Problematic severe asthma in children, not one problem but many: a $\mathrm{GA}^{2} \mathrm{LEN}$ initiative. Eur Respir J 2010; 36: 196-201.

21 Lødrup Carlsen KC, Hedlin G, Bush A, et al. Assessment of problematic severe asthma in children. Eur Respir J 2011; 37: 432-440.

22 Bush A, Pedersen S, Hedlin G, et al. Pharmacological treatment of severe, therapy-resistant asthma in children: what can we learn from where? Eur Respir J 2011; 38: 947-958.

23 Moss S, McKean M, Spencer D. The oral corticosteroid sparing effect of omalizumab in patients with severe chronic asthma: is there a difference when you become 12 years old? Eur Respir J 2011; 38: Suppl. 55, 883s.

24 Pitts J, Sheikh S, McCoy K. Safety and efficacy of omalizumab in children with allergic asthma. Eur Respir J 2011; 38: Suppl. 55, 883s.

25 Frost S, Lesley B, Lakhani Y, et al. Omalizumab in paediatric asthma: importance of multi-disciplinary assessment to identify the eligible patients. Eur Respir J 2011; 38: Suppl. 55, 883s.

26 Szefler SJ, Zeiger RS, Haselkorn T, et al. Economic burden of impairment in children with severe or difficult-to-treat asthma. Ann Allergy Asthma Immunol 2011; 107: 110-119.

27 Busse WW, Morgan WJ, Gergen PJ, et al. Randomized trial of omalizumab (anti-IgE) for asthma in inner-city children. $N$ Engl J Med 2011; 364: 1005-1015.

28 Custovic A, Simpson A, Bardin PG, et al. Allergy is an important factor in asthma exacerbation: a pro/con debate. Respirology 2010; 15: 1021-1027.

29 Sly PD, Kusel M, Holt PG. Do early-life viral infections cause asthma? J Allergy Clin Immunol 2010; 125: 1202-1205.

30 Callaway Z, Kim CK. Respiratory viruses, eosinophilia and their roles in childhood asthma. Int Arch Allergy Immunol 2011; 155: $1-11$.

31 Busse WW, Lemanske RF Jr, Gern JE. Role of viral respiratory infections in asthma and asthma exacerbations. Lancet 2010; 376: 826-834.
32 Edwards M, Regamey N, Vareille M, et al. Impaired innate immunity to rhinovirus in severe asthmatic children. Eur Respir J 2011; 38: Suppl. 55, 622s.

33 Bartlett N, Glanville N, Walton R, et al. Different modes of allergen - rhinovirus interaction control chemokine production. Eur Respir J 2011; 38: Suppl. 55, 624s.

34 Savenije OE, Granell R, Caudri D, et al. Comparison of childhood wheezing phenotypes in 2 birth cohorts: ALSPAC and PIAMA. J Allergy Clin Immunol 2011; 127: 1505-1512.

35 van de Kant KDG, Jansen M, Klaassen EMM, et al. Airway inflammation, lung function and wheezing phenotypes in preschool children. Eur Respir J 2011; 38: Suppl. 55, 249s.

36 O'Reilly R, Oates T, Zhu J, et al. More airway smooth muscle in preschool children increases risk of future asthma. Eur Respir 2011; 38: Suppl. 55, 249s.

37 Brasier $\mathrm{AR}$, Victor $\mathrm{S}, \mathrm{Ju} \mathrm{H}$, et al. Predicting intermediate phenotypes in asthma using bronchoalveolar lavage-derived cytokines. Clin Transl Sci 2010; 3: 147-157.

38 James A, Nordlund B, Konradsen J, et al. The chitinase-like protein YKL-40 is elevated in children with severe asthma. Eur Respir J 2011; 38: Suppl. 55, 585s.

39 Schoos AMM, Chawes BLK, Bønnelykke K, et al. Airway inflammation is a continuous trait in children regardless of asthma symptoms. Eur Respir J 2011; 38: Suppl. 55, 250s.

40 Bhavnani SK, Victor S, Calhoun WJ, et al. How cytokines cooccur across asthma patients: from bipartite network analysis to a molecular-based classification. J Biomed Inform 2011; 44: Suppl. 1, S24-30.

41 Bousquet J, Anto J, Auffray C, et al. MeDALL (Mechanisms of the Development of ALLergy): an integrated approach from phenotypes to systems medicine. Allergy 2011; 66: 596-604.

42 Ober C, Yao TC. The genetics of asthma and allergic disease: a 21st century perspective. Immunol Rev 2011; 242: 10-30.

43 Melén E, Himes BE, Brehm JM, et al. Analyses of shared genetic factors between asthma and obesity in children. J Allergy Clin Immunol 2010; 126: 631-637.

44 Torjussen TM, Lødrup Carlsen KC, Munthe-Kaas MC, et al. Alpha-nicotinic acetylcholine receptor and tobacco smoke exposure: effects on bronchial hyperresponsiveness in children. Pediatr Allergy Immunol 2012; 23: 40-49.

45 Custovic A, Rothers J, Stern D, et al. Effect of day care attendance on sensitization and atopic wheezing differs by Toll-like receptor 2 genotype in 2 population-based birth cohort studies. J Allergy Clin Immunol 2011; 127: 390-397.

46 Bukvic BK, Blekic M, Aberle N, et al. Opposite effect of endotoxin exposure with different MD-2 genotypes on asthma in children. Eur Respir J 2011; 38: Suppl. 55, 250s.

47 Breton CV, Byun HM, Wang X, et al. DNA methylation in the arginase-nitric oxide synthase pathway is associated with exhaled nitric oxide in children with asthma. Am J Respir Crit Care Med 2011; 184: 191-197.

48 Munthe-Kaas MC, Torjussen TM, Gervin K, et al. CD14 polymorphisms and serum CD14 levels through childhood: a role for gene methylation? J Allergy Clin Immunol 2010; 125: 1361-1368.

49 Martino D, Prescott S. Epigenetics and prenatal influences on asthma and allergic airways disease. Chest 2011; 139: 640-647.

50 Postma DS, O'Byrne PM, Pedersen S. Comparison of the effect of low-dose ciclesonide and fixed-dose fluticasone propionate and salmeterol combination on long-term asthma control. Chest 2011; 139: 311-318

51 Brand P, Jagannath K, Garcia Garcia ML, et al. Randomized placebo-controlled study of ciclesonide in preschool children with recurrent wheeze and a positive asthma predictive index or atopy. Eur Respir J 2011; 38: Suppl. 55, 250s.

52 Lob SH, Boer JH, Porter PG, et al. Promoting best-care practices in childhood asthma: quality improvement in community health centers. Pediatrics 2011; 128: 20-28. 
53 Bruzzese JM, Sheares BJ, Vincent EJ, et al. Effects of a schoolbased intervention for urban adolescents with asthma: a controlled trial. Am J Respir Crit Care Med 2011; 183: 998-1006.

54 Chini L, Iannini R, Chianca M, et al. Happy air ${ }^{\circledR}$, a successful school-based asthma educational and interventional program for primary school children. J Asthma 2011; 48: 419-426.

55 Sheikh S, Chrysler M, McCoy K. Asthma care community program focusing on primary care (PC) education: train the trainer. Eur Respir J 2011; 38: Suppl. 55, 781s.

56 Bird D, Perkins G, Culley L, et al. A systematic review of underlying reasons for barriers to asthma management in ethnic minority children. Eur Respir J 2011; 38: Suppl. 55, 881s.

57 Davis SQ, Krishnan JA, Lee K, et al. Effect of a community-wide asthma intervention on appropriate use of inhaled corticosteroids. J Urban Health 2011; 88: Suppl. 1, 144-155.

58 Sunshine J, Song L, Krieger J. Written action plan use in innercity children: is it independently associated with improved asthma outcomes? Ann Allergy Asthma Immunol 2011; 107: 207-213.

59 Muraro A, Clark A, Beyer K, et al. The management of the allergic child at school: EAACI/GA ${ }^{2} \mathrm{LEN}$ Task Force on the allergic child at school. Allergy 2010; 65: 681-689.

60 Plant BJ, Ramsey B, Yen K, et al. Late-breaking abstract: VX-770, an investigational CFTR potentiator, in subjects with CF and the G551D mutation. Eur Respir J 2011; 38: Suppl. 55, 848s.

61 Ramsey BW, Davies J, McElvaney NG, et al. A CFTR potentiator in patients with cystic fibrosis and the G551D mutation. N Engl J Med 2011; 365: 1663-1672.

62 Sermet-Gaudelus I, Boeck KD, Casimir GJ, et al. Ataluren (PTC124) induces cystic fibrosis transmembrane conductance regulator protein expression and activity in children with nonsense mutation cystic fibrosis. Am J Respir Crit Care Med 2010; 182: 1262-1272.

63 Accurso FJ, Moss RB, Wilmott RW, et al. Denufosol tetrasodium in patients with cystic fibrosis and normal to mildly impaired lung function. Am J Respir Crit Care Med 2011; 183: 627-634.

64 Bilton $\mathrm{D}$, Robinson $\mathrm{P}$, Cooper $\mathrm{P}$, et al. Inhaled dry powder mannitol in cystic fibrosis: an efficacy and safety study. Eur Respir J 2011; 38: 1071-1080.

65 Pillarisetti N, Williamson E, Linnane B, et al. Infection, inflammation, and lung function decline in infants with cystic fibrosis. Am J Respir Crit Care Med 2011; 184: 75-81.

66 Lum S, Gustafsson P, Ljungberg H, et al. Early detection of cystic fibrosis lung disease: multiple-breath washout versus raised volume tests. Thorax 2007; 62: 341-347.

67 Stick SM, Brennan S, Murray C, et al. Bronchiectasis in infants and preschool children diagnosed with cystic fibrosis after newborn screening. J Pediatr 2009; 155: 623-628.

68 Thia L, Hoo AF, Nguyen TD, et al. Improvement in lung function during the 1st year of life in infants diagnosed with CF through newborn screening (NBS). Eur Respir J 2011; 38: Suppl. 55, 848s.

69 Simpson SJ, Logie KM, Schulzke S, et al. Infection and inflammation does not effect ventilation distribution in infants with cystic fibrosis (CF). Eur Respir J 2011; 38: Suppl. 55, 848s.

70 Lindblad A, Aljassim F, Gustafsson P. Lung clearance index (LCI) at age 1-4 years vs lung function and chest X-ray (CXR) scores at age 7 years in children with CF. Eur Respir J 2011; 38: Suppl. 55, 832s-833s.

71 Mott L, Gonzalez-Graniel K, Murray C, et al. Comparison of cystic fibrosis structural lung disease detected by inspiratory and expiratory chest CT scans in infants and preschool children. Eur Respir J 2011; 38: Suppl. 55, 848s-849s.

72 Eichinger M, Heussel CP, Kauczor HU, et al. Computed tomography and magnetic resonance imaging in cystic fibrosis lung disease. J Magn Reson Imaging 2010; 32: 1370-1378.

73 Eichinger M, Fritzsching E, Kopp-Schneider A, et al. Magnetic resonance imaging (MRI) as a non-invasive, radiation-free imaging modality to study the onset and progression of lung disease in infants and young children with cystic fibrosis. Eur Respir J 2011; 38: Suppl. 55, 849s.

74 Thursfield R, Bush A, Adams A, et al. What is the significance of Aspergillus fumigatus in BAL in children with cystic fibrosis. Eur Respir J 2011; 38: Suppl. 55, 849s.

75 Adams A, Thursfield R, Bush A. Effect of recurrent growth of Aspergillus on lung function in paediatric population with cystic fibrosis (CF). Eur Respir J 2011; 38: Suppl. 55, 834s.

76 Vanderhelst E, De Meirleir L, Verbanck S, et al. Prevalence and impact on FEV1 decline of methicillin-resistant Staphylococcus aureus infection in patients with cystic fibrosis. Eur Respir J 2011; 38: Suppl. 55, 834s.

77 Gartner S, Mumany M, Ferrer A, et al. Stenotrophomonas maltophilia and Achromobacter xylosoxidans in cystic fibrosis patients. Eur Respir J 2011; 38: Suppl. 55, 789s.

78 Dewaele E, Goeminne P, Scheers H, et al. Impact of Stenotrophomonas maltophilia in cystic fibrosis: a retrospective analysis. Eur Respir J 2011; 38: Suppl. 55, 789s.

79 Christiaens L, Goeminne P, Dupont L. Achromobacter xylosoxidans: friend or foe? Eur Respir J 2011; 38: Suppl. 55, 789s.

80 Asherova I, Monachova S, Ershova M, et al. Prevalence and reservoirs of $A$. xylosoxidans and $S$. maltophilia in cystic fibrosis center. Eur Respir J 2011; 38: Suppl. 55, 834s.

81 Wat G, Gelder C, Hibbits F, et al. The role of respiratory viruses in cystic fibrosis. J Cyst Fibr 2008; 7: 320-328.

82 Kieninger E, Vareille M, Alves MP, et al. Deficient production of IFN-stimulated genes upon rhinovirus infection in cystic fibrosis airway epithelial cells. Eur Respir J 2011; 38: Suppl. 55, 39s.

83 Kieninger E, Tapparel C, Kronig MN, et al. Frequent detection of rhinovirus in bronchoalveolar lavage samples from children with cystic fibrosis. Eur Respir J 2011; 38: Suppl. 55, 833s.

84 Robroeks C, Jöbsis Q, Hendriks H, et al. The value of lung function monitoring by means of a home monitor in patients with cystic fibrosis. Eur Respir J 2011; 38: Suppl. 55, 40s.

85 Dijk N, McKay K, Barzi F, et al. Newborn screening for cystic fibrosis improves lung function and growth at time of transfer to adult care. Eur Respir J 2011; 38: Suppl. 55, 849s.

86 Cohen-Cymberknoh M, Yaakov Y, Kerem E, et al. Intestinal current measurement (ICM) as a new diagnostic test for cystic fibrosis (CF). Eur Respir J 2011; 38: Suppl. 55, 39s.

87 Dracea LL, Pop L. Preventable deaths and better outcomes in CF: need for organising care at European standards in developing countries. Eur Respir J 2011; 38: Suppl. 55, 790s.

88 Bisgaard H, Hermansen MN, Buchvald F, et al. Childhood asthma after bacterial colonization of the airway in neonates. N Engl J Med 2007; 357: 1487-1495.

89 van de Kant KDG, Klaassen EMM, van Aerde K, et al. Bacterial colonisation/infection and airway inflammation in preschool children with recurrent wheeze. Eur Respir J 2011; 38: Suppl. 55, 69s.

90 White JH. Vitamin D signaling., infectious diseases and regulation of innate immunity. Infect Immun 2008; 76: 3837-3843.

91 Pillai AMA, Palanivel V. Subclinical vitamin D deficiency and acute respiratory tract infections in children: a systematic review. Eur Respir J 2011; 38: Suppl. 55, 70s.

92 Manaseki-Holland S, Qader G, Isaq Masher M, et al. Effects of vitamin $\mathrm{D}$ supplementation to children diagnosed with pneumonia in Kabul: a randomised controlled trial. Trop Med Int Health 2010; 15: 1148-1155.

93 Urashima M, Segawa T, Okazaki M, et al. Randomized trial of vitamin D supplementation to prevent seasonal influenza A in schoolchildren. Am J Clin Nutr 2010; 91: 1255-1260.

94 Zhang L, Mendoza-Sassi RA, Wainwright C, et al. Nebulized hypertonic saline solution for acute bronchiolitis in infants. Cochrane Database Syst Rev 2008; 4: CD006458.

95 Teunissen J, Hochs AHJ, Vaessen-Verberne AAP, et al. Effect of inhaled hypertonic saline solution to treat infants hospitalized 
with viral bronchiolitis. Eur Respir J 2011; 38: Suppl. 55, 293s-294s.

96 Nenna R, Papasso S, Battaglia M, et al. 7\% hypertonic saline and hyaluronic acid in the treatment of infants mild-moderate bronchiolitis. Eur Respir J 2011; 38: Suppl. 55, 294 s.

97 Leader S, Kohlhase K. Recent trends in severe respiratory syncytial virus (RSV) among US infants, 1997 to 2000. J Pediatr 2003; 143: Suppl. 5, S127-S132.

98 Buesch $\mathrm{K}$, Khong H, Gooch $\mathrm{K}$. Evaluating the risk of lower respiratory tract infection (LRTI) hospitalizations due to respiratory distress syndrome (RDS) in late preterm. Eur Respir J 2011; 38: Suppl. 55, 294s

99 Shefali-Patel D, Alcazar M, Bowden E, et al. Healthcare utilisation and related cost of care in the first two years related to RSV hospitalisation in infants born at 32 to 35 weeks gestation. Eur Respir J 2011; 38: Suppl. 55, 72s-73s.

100 Barbato A, Frischer T, Kuehni CE, et al. Primary ciliary dyskinesia: a consensus statement on diagnostic and treatment approaches in children. Eur Respir J 2009; 34: 1264-1276.

101 Nauta F, Pals G, Daniels H, et al. Diagnosis of primary ciliary dyskinesia in a Dutch cohort of 63 pediatric patients: an overview. Eur Respir J 2011; 38: Suppl. 55, 71s.

102 Hartung JC, Kelm M, Fischer H, et al. Influence of mask leak on applied volumes and pressures during simulated resuscitation of neonates. Eur Respir J 2011; 38: Suppl. 55, 332s.

103 Gorovenko N, Kyryachenko S, Rossokha Z. The influence of angiotensin-converting enzyme (ACE) genotype on the development of severe perinatal asphyxia in the neonates. Eur Respir I 2011; 38: Suppl. 55, 792s.

104 Chowdhury O, Lee S, Hannam S, et al. Appropriate level of volume targeting for ventilated infants born at or near term. Eur Respir J 2011; 38: Suppl. 55, 332s.

105 Chowdhury O, Kayode S, Lee S, et al. Spontaneous respiratory activity during mechanical ventilation of term born infants. Eur Respir J 2011; 38: Suppl. 55, 792s.

106 Bhandari N, Bhandari R, Kandel P, et al. Neonatal resuscitation at the community level. Eur Respir J 2011; 38: Suppl. 55, 331s-332s.

107 Withers A, Wilson A, Sharp M, et al. Predicting the safety of air travel in ex-premature infants. Eur Respir J 2011; 38: Suppl. $55,793 \mathrm{~s}$

108 Vrijlandt EJ, Boezen HM, Gerritsen J, et al. Respiratory health in prematurely born preschool children with and without bronchopulmonary dysplasia. J Pediatr 2007; 150: 256-261.

109 Choukroun ML, Feghali-Caron H, Marquant F, et al. Determinants of lung function in school aged children prematurely born before 32 weeks of gestation. Eur Respir J 2011; 38: Suppl. 55, 792s-793s.

110 Lidberg K, Kosma P, Hedlin G, et al. Infant spirometry at three months after birth in term and preterm infants. Eur Respir J 2011; 38: Suppl. 55, 793s

111 Loeve $\mathrm{M}$, van Hal $\mathrm{PT}$, Robinson $\mathrm{P}$, et al. The spectrum of structural abnormalities on CT scans from patients with CF with severe advanced lung disease. Thorax 2009; 64: 876-882.

112 Young AC, Wilson JW, Kotsimbos TC, et al. The impact of nocturnal oxygen desaturation on quality of life in cystic fibrosis. J Cyst Fibros 2011; 10: 100-106.

113 Stenekes SJ, Hughes A, Grégoire MC, et al. Frequency and selfmanagement of pain, dyspnea, and cough in cystic fibrosis. J Pain Symptom Manage 2009; 38: 837-848.

114 Bruijn M, Jansen E, Klapwijk T, et al. Association between Creactive protein levels and outcome in acute lung injury in children. Eur Respir J 2011; 38: Suppl. 55, 794s.

115 Benden C, Aurora P, Edwards LB, et al. The Registry of the International Society for Heart and Lung Transplantation: Fourteenth Pediatric Lung and Heart-Lung Transplantation Report - 2011. J Heart Lung Transplant 2011; 30: 1123-1132.
116 Domínguez-Gil B, Haase-Kromwijk B, Van Leiden $\mathrm{H}$, et al. Current situation of donation after circulatory death in European countries. Transplant Int 2011; 24: 676-686.

117 Kotecha SJ, Watkins WJ, Heron J, et al. Spirometric lung function in school-age children: effect of intrauterine growth retardation and catch-up growth. Am J Respir Crit Care Med 2010; 181 969-974.

118 Kotecha SJ, Watkins WJ, Herrick D, et al. Effect of late preterm birth on longitudinal lung spirometry in children. Eur Respir J 2011; 38: Suppl. 55, 602s.

119 Vollsaeter M, Røksund O, Eide GE, et al. Longitudinal development of lung function in extremely preterm infants. Eur Respir $J$ 2011; 38: Suppl. 55, 271s.

120 Vogt H, Lindström K, Bråbäck L, et al. Preterm birth and inhaled corticosteroid usage in 6-19-year-olds - a Swedish national cohort study. Eur Respir J 2011; 38: Suppl. 55, 271s.

121 Turner SW, Palmer LJ, Rye PJ, et al. The relationship between infant airway function, childhood airway responsiveness, and asthma. Am J Respir Crit Care Med 2004; 169: 921-927.

122 Martinez FD, Wright AL, Taussig LM, et al. Asthma and wheezing in the first six years of life. The Group Health Medical Associates. N Engl J Med 1995; 332: 133-138.

123 Duijts L, Granell R, Sterne JAC, et al. Association of wheezing phenotypes in the first 7 years of life with fractional exhaled nitric oxide and lung function in adolescence. The ALSPAC study. Eur Respir J 2011; 38: Suppl. 55, 602s.

124 Henderson J, Granell R, Heron J, et al. Associations of wheezing phenotypes in the first 6 years of life with atopy, lung function and airway responsiveness in mid-childhood. Thorax 2008; 63: 974-980.

125 Mullane D, Turner S, Cox D, et al. Early life antecedents of persistent wheeze in young adults. Eur Respir J 2011; 38: Suppl. $55,271 \mathrm{~s}$

126 van der Gugten A, Uiterwaal C, Verheij T, et al. Reduced neonatal lung function and wheezing illnesses during the first 5 years of life. Eur Respir J 2011; 38: Suppl. 55, 602s-603s.

127 Turner S, Prabhu N, Cutts R, et al. First and second trimester fetal size and asthma outcomes at age ten years. Eur Respir J 2011; 38: Suppl. 55, 270s.

128 Sonnenschein-van der Voort A, de Jongste J, Hofman A, et al. Fetal and infant growth is associated with wheezing in preschool children. The Generation R study. Eur Respir J 2011; 38: Suppl. 55, 270s-271s.

129 Mortimer K, Neugebauer R, Lurmann F, et al. Air pollution and pulmonary function in asthmatic children: effects of prenatal and lifetime exposures. Epidemiology 2008; 19: 550-557.

130 Friedman NJ, Zeiger RS. The role of breast-feeding in the development of allergies and asthma. J Allergy Clin Immunol 2005; 115: 1238-1248.

131 Strippoli MPF, Hallberg A, Beardsmore CS, et al. Early life exposure to locally-generated PM10 and lung function measurements at school-age. Eur Respir J 2011; 38: Suppl. 55, 603s.

132 Dogaru CM, Narayanan M, Strippoli MPF, et al. Association between breastfeeding and lung volumes and alveolar size. Eur Respir J 2011; 38: Suppl. 55, 603s.

133 Wong G, Leung TF, Yung E. Indoor endotoxin and respiratory symptoms in urban schoolchildren. Eur Respir J 2011; 38: Suppl. 55, 272s.

134 Kusel MM, de Klerk NH, Kebadze T, et al. Early-life respiratory viral infections., atopic sensitization., and risk of subsequent development of persistent asthma. J Allergy Clin Immunol 2007; 119: 1105-1110.

135 Garcia-Marcos L, Mallol J, Sole D, et al. International study of wheezing in infants (EISL): how latitude modifies the associations between risk and protective factors for recurrent wheeze during the first year of life. Eur Respir J 2011; 38: Suppl. 55, 602s. 
136 Garcia-Marcos L, Mallol J, Sole D, et al. Factors associated to an earlier wheezing episode during the first year of life in Europe and Latin America: The EISL study. Eur Respir J 2011; 38: Suppl. 55,272 s.

137 Strippoli MPF, Pescatore AM, Spycher BD, et al. Natural history of recurrent cough in children. Eur Respir J 2011; 38: Suppl. $55,269 \mathrm{~s}$.

138 Midulla F, de Blic J, Barbato A, et al. Flexible endoscopy of paediatric airways. Eur Respir J 2003; 22: 698-708.

139 Gokdemir Y, Cakir E, Erdem E, et al. The role of flexible bronchoscopy in evaluation of recurrent and persistant pneumonia in children. Eur Respir J 2011; 38: Suppl. 55, 251s.

140 Douros K, Alexopoulou E, Nicopoulou A, et al. Bronchoscopic and high resolution CT findings in children with chronic wet cough. Eur Respir J 2011; 38: Suppl. 55, 251s.

141 Marchant JM, Masters IB, Taylor SM, et al. Evaluation and outcome of young children with chronic cough. Chest 2006; 129: 1132-1141.

142 Mondejar-Lopez P, Pastor-Vivero MD, Bragado-Alcaraz E, et al. Airway-related complications in preterm infants who were intubated at birth. Eur Respir J 2011; 38: Suppl. 55, 250s-251s.
143 Downing GJ, Kilbride HW. Evaluation of airway complications in high-risk preterm infants: application of flexible fiberoptic airway endoscopy. Pediatrics 1995; 95: 567-572.

144 de Blic J, Midulla F, Barbato A, et al. Bronchoalveolar lavage in children. Eur Respir J 2000; 15: 217-231.

145 Mondejar-Lopez P, Pastor-Vivero MD, Bragado-Alcaraz E, et al. Bacterial cultures in bronchoalveolar lavage fluid in children with chronic respiratory conditions. Eur Respir J 2011; 38: Suppl. 55, 252s.

146 Snijders D, Bazzan E, Bugin S, et al. BAL eosinophil counts and specific clinical phenotypes of asthmatic and/or atopic children. Eur Respir J 2011; 38: Suppl. 55, 251s.

147 de Mir I, Moreno A, Gorriz P, et al. The role of transbronchial biopsy in pediatric patients. Eur Respir J 2011; 38: Suppl. 55, 252s.

148 Visner GA, Faro A, Zander DS. Role of transbronchial biopsies in pediatric lung diseases. Chest 2004; 126: 273-280.

149 Modaresi M, Gorji M, Ashjai B, et al. Foreign body aspiration in children: single center experience during a 4 years period. Eur Respir J 2011; 38: Suppl. 55, 251s.

150 Midulla F, Guidi R, Barbato A, et al. Foreign body aspiration in children. Pediatr Int 2005; 47: 663-668.

151 Svanes C, Sunyer J, Plana E, et al. Early life origins of chronic obstructive pulmonary disease. Thorax 2010; 65: 14-20. 